\title{
“O combinado" entre professores: marcas da (des)vitalidade do coletivo
}

\author{
Kátia Diolina* \\ Luzia Bueno**
}

\begin{abstract}
Resumo
Este artigo, recorte dos resultados e discussões de uma tese de doutorado (DIOLINA, 2016), visa a problematizar o papel do coletivo na produção de soluções em razão dos desafios diários vividos pelos professores, conforme revelado em discussão em grupo com professores da rede pública do estado de São Paulo. Trata-se da análise de textos (orais, posteriormente transcritos) produzidos pelos professores e de um estudo engajado nos referenciais teórico-metodológicos do Interacionismo Sociodiscursivo (BRONCKART, 2006; MACHADO; BRONCKART, 2009; MACHADO et al., 2007), nos da Ergonomia Francesa (AMIGUES, 2004; CAROLY, 2010) e nos da Clínica da Atividade (CLOT, 2006; 2010; KOSTULSKI et al., 2011). O estudo permitiu reafirmar e melhor compreender como o papel do coletivo é significativo e fundamental para o bemestar da atividade de trabalho, bem como levantar aspectos que podem desvitalizá-lo (DIOLINA, 2016).

Palavras-chave: Papel do coletivo; Trabalho do professor; Características de (des)vitalidade.
\end{abstract}

\section{"The deal" between teachers: signs of the collective's (lack of) vitality}

\begin{abstract}
Presenting the results and discussions of a doctoral thesis (DIOLINA, 2016), this paper aims to question the role of the collective in the production of solutions based on the daily challenges faced by teachers, as revealed in a group discussion with teachers from Sao Paulo public schools. It is about an analysis of texts (oral texts, later transcribed) produced by these teachers and a study engaged in the theoretical-methodological references of the Socio-Discursive Interactionism (BRONCKART, 2006; MACHADO, BRONCKART, 2009; MACHADO et al., 2007), of the French Ergonomics (AMIGUES, 2004; CAROLY, 2010) and of the Clinic of Activity (CLOT, 2006, 2010; KOSTULSKI et al., 2011). This study allowed us to reaffirm and improve our understanding on how the role of the collective is significant and fundamental for the well-being of the work activity, as well as to raise aspects that may cause its lack of vitality (DIOLINA, 2016).

Keywords: Collective's role; Teacher's work; Characteristics of (a lack of) vitality.
\end{abstract}

\section{Introdução}

Abordar os diversos desafios da profissão docente é sempre necessário e muitos estudos já se debruçaram sobre o tema, como os de Esteve (1999) a respeito do mal-estar docente iniciado nos anos 90. Machado e Magalhães (2002) alertaram sobre os efeitos dos desafios na atividade do professor, em que os múltiplos papéis a cumprir, os baixos salários, o aumento de horas trabalhadas, o aumento de violência, o excesso de alunos, os alunos desmotivados e indisciplinados entre outros levam a um sofrimento físico e psíquico dos professores. Jedlicki e Yancovic (2010) defendem a concepção de desprofissionalização docente (JEDLICKI; YANCOVIC, 2010), em que o professor se torna muito mais um executor que um criador $\mathrm{e}$ transformador de sua atividade, mais um objeto de ações alheias do que um protagonista na realização da atividade de trabalho, perdendo seu poder de agir e levando-o ao isolamento.

\footnotetext{
*Endereço eletrônico: katiadio@gmail.com

***Endereço eletrônico: luzia_bueno@uol.com.br
}

Daí a importância em privilegiar como os professores, diante de tantos desafios, produzem estratégias para sustentar e prover a atividade diária de trabalho. Uma reflexão dessa ordem foi inscrita na programação do III Colóquio Internacional de Clínica da Atividade (III CICA) ${ }^{1}$, em que tivemos a oportunidade de contribuir com a organização de um simpósio, do qual este artigo é uma versão revisada do que foi apresentado na ocasião.

Partimos de uma abordagem em que a atividade docente é (re)significada pela perspectiva do professor em condições concretas de trabalho. Filiamo-nos, então, a uma perspectiva históricocultural do desenvolvimento humano e a um enfoque discursivo e ideológico da linguagem que defendem que é na ação que o conhecimento emerge, nas situações da experiência humana prática e linguageira, como, os estudos desenvolvidos pelo Grupo ALTER-CNPq e de seus referenciais, a saber: os aportes do Interacionismo Sociodiscursivo (BRONCKART, 2006); os do 
grupo ERGAPE (AMIGUES, 2004); o quadro teórico-metodológico da Clínica da Atividade (CLOT, 2006; 2010; KOSTULSKI et al., 2011); e as características de vitalidade do coletivo (CAROLY, 2010; CAROLY; BARCELLINI, 2013).

Imbuídos desse arcabouço teóricometodológico, neste artigo em particular, focamos uma situação desafiante ${ }^{3}$ que aborda a estratégia coletiva denominada "o combinado" que fora experimentada pelos professores-participantes. Isso é importante porque as discussões podem nos indicar como a estratégia utilizada em razão dos desafios da profissão contribuiu para aliviar ou não as tensões, os problemas da atividade de trabalho, assim como podem nos apontar o papel do coletivo nesse processo, por meio do levantamento das características de vitalidade do coletivo (CAROLY, 2010) e das marcas que o desvitalizam (DIOLINA, 2016).

Reforçamos que o coletivo é central e decisivo neste estudo, pois o compreendemos como recurso da profissão, sendo decisivo para a legitimação dos estilos individuais e das transformações das regras, bem como para a ajuda mútua dentre as diferentes situações que desafiam o professor (CLOT, 2010). Por isso é importante, para nós, identificar seu papel na possível solução dos desafios diários da profissão. Sendo assim, neste artigo, visamos a problematizar o papel do coletivo na produção de soluções em razão dos desafios diários vividos pelos professores, por meio da análise da situação desafiante: "o combinado", um agir combinado /planejado previamente pelos professores.

Particularmente, desenvolvemos uma pesquisa de doutorado com oito professores do ensino fundamental $\left(6^{\circ}\right.$ ao $9^{\circ}$ ano) e médio sobre os desafios vividos no cotidiano e as possíveis estratégias na resolução dos mesmos. Evidentemente que vários desafios e diferentes estratégias foram apontados nos textos dos professores, como, a estratégia do "combinado". Para a produção dos dados, primeiro, utilizamos a instrução ao sósia com cada professor, isto é, questionamos sobre como substituí-los na atividade diária da profissão, solicitando instruções/orientações sobre como agir. Em seguida, transcrevemos e relemos (pesquisadora e professores-participantes) as instruções dadas, buscando levantar e discutir em grupo os temas (desafios e estratégias) mais significativos para cada participante. Durante as discussões em grupo (textos orais, posteriormente transcritos para análise), a estratégia do "combinado" foi uma das mais significativas em relação ao desafio diário da indisciplina dos alunos, razão de discuti-la neste trabalho.

Para tanto, a seguir, iniciamos nossas discussões acerca dos conceitos que assumimos sobre a atividade de trabalho e a atividade do professor; para, então, na seção seguinte, defender o coletivo como recurso primordial para a vitalidade do desenvolvimento e transformação da atividade. Na terceira seção, detalhamos nossos procedimentos metodológicos, contextualizando e detalhando a produção e os critérios de seleção e de análise dos dados. Na quarta seção, expomos os resultados e discussões de análise, buscando problematizar o papel do coletivo na elaboração e aplicação da estratégia. Por fim, tecemos nossas considerações.

\section{A atividade de trabalho e a atividade do professor}

Nesta seção, a proposta é discutir a complexidade das concepções relativas à atividade de trabalho e à atividade do professor. Para isso, iniciamos destacando a distância existente entre a tarefa tal como é dada (a prescrição ou normas de condutas sobre como realizar uma atividade de trabalho) e a atividade tal como foi concretizada pelo profissional. A tarefa seria a prescrição, ou mesmo, a autoprescrição, e a atividade realizada é aquela executada, exercida, efetivamente, diante dos desafios e das soluções existentes (AMIGUES, 2004).

Nessa relação entre prescrições e atividade realizada, abre-se uma lacuna entre o possível de ser realizado e o que se idealiza. A ação empregada pelo sujeito profissional durante o exercício de seu trabalho é, então, uma prática "mais ou menos conflituosa para regular essa distância (...) e construir recursos que contribuirão para seu desenvolvimento profissional e pessoal" (AMIGUES, 2004, p. 40). O profissional, portanto, ao buscar vencer os possíveis conflitos durante a realização da atividade de trabalho, pode produzir e, ao mesmo tempo, desenvolver diferentes estratégias que se tornam capacidades para seu agir.

Segundo Clot (2010), além da instância impessoal (as prescrições), a atividade de trabalho é realizada por um sujeito único (instância pessoal), bem como pode ser realizada de forma cooperativa entre colegas (instância interpessoal) e traz consigo uma bagagem histórica dos modos de exercê-la que 
são compartilhados entre os profissionais (instância transpessoal).

Assim, a atividade de trabalho é um fenômeno histórico e social, não é um objeto qualquer, externo, isolado, indiferente às pessoas e ao contexto inserido. Ao contrário, a atividade de trabalho é realizada por pessoas, para outras pessoas, em diferentes lugares, logo, é uma atividade dirigida. Dirigida "não só pelo comportamento do sujeito ou dirigida por meio do objeto da tarefa, mas também dirigida aos outros" (CLOT, 2006, p. 97).

A atividade se dirige ao profissional que, para realizá-la, precisa organizar o meio/ambiente (o objeto), numa relação direta e indireta com as diferentes atividades de colegas de profissão, chefes, clientes (o outrem), sendo que essa tríade relação é sempre mediada por instrumentos materiais ou simbólicos. Essa tríade relação existe em uma tensão, num conflito que é saudável, pois favorece, faz emergir o desenvolvimento da atividade, sendo fonte de energia da criatividade da atividade (CLOT, 2010).

Com a atividade de trabalho do professor não é diferente. Ela também sofre a distância entre prescrições (autoprescrições) e atividade realizada, bem como apresenta um caráter real em que os impedimentos, as idealizações, o realizado e o não realizado abarcam o todo da atividade. O professor, ao exercer sua atividade, emprega sua subjetividade, sua singularidade e seu estilo (instância pessoal) e adequa/readequa constantemente a atividade conforme as prescrições que tem (instância impessoal), conforme a ajuda mútua de que dispõe (instância interacional) e conforme os modos de fazer (instância transpessoal) de que se apropriou ao longo de sua carreira. Sendo que esse processo tampouco é isolado, pelo contrário (MACHADO, 2007), insere-se numa tríade relação em que o professor precisa gerir o meio (sala de aula, por exemplo) e a interação direta e indireta com os diferentes outrem (alunos, pais, colegas, comunidade etc.) por meio da mediação de instrumentos materiais e simbólicos disponíveis ou não (textos, vídeos, data-show, carteiras, bilhete, entre tantos). Além disso, a atividade de trabalho do professor encontra-se ancorada num contexto sóciohistórico e numa rede de relações de poder políticoeducacionais e pedagógicas que implica um sistema de ensino e um sistema educacional (MACHADO, 2007).
Além de toda essa complexidade, os novos cenários do mundo globalizado (novas tecnologias, aceleração de produção, trabalhadores polivalentes) afetam o trabalho do professor. Particularmente, as exigências de um ensino de qualidade dentro de um sistema de massa, de violência, de desvalorização e de precarização do trabalho. Essa situação tem aumentado o adoecimento e o afastamento de professores (GOMES; BRITO, 2006). Como auxiliá-los? Confiamos que as discussões acerca do papel do coletivo podem contribuir com algumas reflexões, conforme destacamos a seguir.

\section{O papel do coletivo}

Nesta seção, o objetivo é discutir o papel do coletivo em prol de salientar de que maneira a vitalidade ou não desse fenômeno pode contribuir com a preservação e o bem-estar da atividade de trabalho e de seus profissionais.

Para tanto, ressaltamos que o termo coletivo não se refere a um agrupamento, a uma coleção de pessoas (de profissionais), de animais, de objetos. Consiste, na verdade, em mais um recurso para o desenvolvimento e para a transformação do profissional (CLOT, 2006; 2010). Essa noção fundamenta-se nas concepções vigotskianas do social como constitutivo do sujeito, de seu pensamento, de suas ações, de seus dizeres, de sua formação e de seu desenvolvimento. Com base nessa perspectiva, o coletivo está diretamente vinculado ao interior do indivíduo e se desenvolve nas trocas exteriores, constituindo-se de uma dimensão social (coletiva) e subjetiva (individual).

Para um profissional realizar um trabalho, ele precisa de algum modo ter acesso ao subentendido da atividade, isto é, à memória dessa atividade que o orientará sobre os modos de realizála. Se a cada vez que um professor fosse dar aula, tivesse que inventar o gênero profissional ministrar aula, a educação seria impossível. Então, assim como ocorre nos estudos da linguagem, em que os gêneros dos discursos são os recursos histórico e culturalmente construídos, são as formas sociais consagradas que possibilitam a atividade de linguagem e são fenômenos de uma ação coletiva, social inserida, desenvolvida e transformada no tempo (história) e espaço (cultura), os gêneros profissionais também o são (CLOT; FAÏTA, 2000). Para os autores, os gêneros de discurso e os gêneros técnicos ${ }^{4}$ constituem juntos os gêneros profissionais 
da atividade, que fornecem "os pressupostos sociais da atividade em curso, que oferta sua capacidade à atividade pessoal: maneiras de começar uma atividade e de finalizá-la, maneiras de conduzir eficazmente" (CLOT; FAÏTA, 2000, p. $12^{5}$ ). Em outros termos "o gênero profissional é história de um grupo e memória impessoal de um local de trabalho" (op. cit., 2006, p. 38) que são compartilhados numa rede de enunciados convencionados e relativamente estáveis praticados por determinado grupo profissional, que coloca em discussão as formas de fazer e de dizer em razão da memória histórica e impessoal, do contexto e dos estilos individuais.

O estilo é desenvolvido ao longo da experiência frente às condições de trabalho reais, que obrigam o profissional a reorganizar, a repensar a atividade de trabalho constantemente. Há, então, dois aspectos principais na ação profissional que atuam de forma mais ou menos conflitante: o estilo e o gênero profissional. Assim como os gêneros profissionais orientam a atividade pessoal, a atividade pessoal, relativamente, desenvolve os gêneros, pois o profissional age por meio deles e, em razão das exigências da situação de ação, ele os readequa, os "ajusta e aperfeiçoa", bem como sua própria ação (CLOT, 2010, p. 126). Os gêneros profissionais da atividade são, então, um meio, um instrumento psicológico, pois exercem uma função psicológica no interior dos indivíduos, orientando sobre como melhor agir frente à determinada situação (CLOT, 2010, p. 90).

Esse fenômeno do gênero profissional situase na instância transpessoal da atividade de trabalho, também denominada de coletivo de trabalho, mas para compreender o coletivo é importante se ater a instância interpessoal, o trabalho coletivo. Ressaltamos que o termo "coletivo" é complexo e implica tanto em "trabalho coletivo" quanto em "coletivo de trabalho". Conceitos distintos, mas complementares. É, na verdade, a "articulação do trabalho coletivo, no qual os operadores/as se engajam, e do coletivo de trabalho do qual eles/elas compartilham" (CAROLY; BARCELLINI, 2013, p. 01, tradução e grifo nosso ${ }^{6}$ ) que o coletivo constitui-se. Trata-se da relação entre duas instâncias (interpessoal e transpessoal) que medeiam o intercâmbio entre as instâncias pessoal e impessoal, em prol seja da legitimidade de estilos seja do uso e da transformação das regras, favorecendo, assim, a reunião e divisão de esforços (instância interpessoal) e o desenvolvimento dos modos, do gênero da atividade (instância transpessoal), conforme o quadro a seguir.

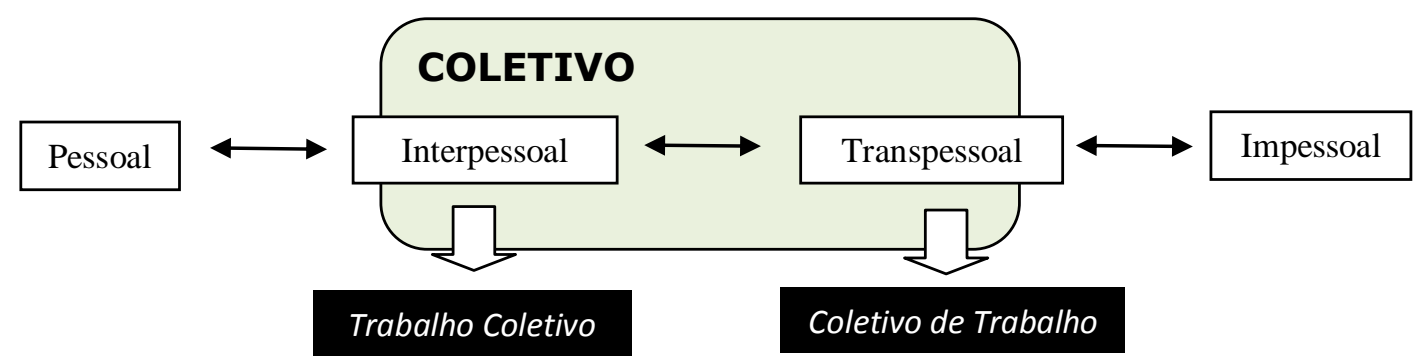

Figura 1: Esquema explicativo das instâncias da atividade de trabalho. Cf. Clot, 2015, em curso.

Todas as instâncias (que não têm ordem hierárquica) relacionam-se, atuando conjunta e dinamicamente em favor do desenvolvimento da atividade. Particularmente, podemos dizer que elas "estão estruturalmente ligadas, em tensão, em conflito, e da fluidez da relação entre elas dependem as questões de saúde e da eficiência do trabalho: tudo está ligado; ou ao menos deveria estar para que a vitalidade profissional não se dissipe" (KOSTULSKI, et al., 2011, p.134, tradução nossa ${ }^{7}$ ).
$\mathrm{O}$ jogo entre essas instâncias nutre a criatividade na atividade de trabalho, mas o excesso da instância impessoal ou a necrose da inter e transpessoal conduzem o indivíduo ao isolamento profissional num conflito direto com as normas, com as regras (KOSTULSKI, et.al, 2011). Com isso, a atividade de trabalho torna-se muito mais individual (instância pessoal) e muito mais regulada por excessivas normas (instância impessoal), em um embate direto entre as instâncias pessoal e 
impessoal, o que significa isolamento profissional, doenças, transgressões de normas e enfraquecimento da criatividade, desvitalizando o coletivo (interpessoal e transpessoal). Por isso, é relevante identificar se o papel do coletivo está sendo atuante, vital ou não. Para Caroly (2010), as características de vitalidade do coletivo podem sinalizar e orientar quanto ao papel do coletivo numa dada atividade de trabalho. $\mathrm{O}$ rol de características elencadas pela autora está disposto a seguir:

1. A capacidade do grupo de se ajustar às dificuldades;

2. A manutenção e preservação da estabilidade dos membros do grupo para estar em harmonia com o trabalho;

3. O surgimento de regras comuns, gestão coletiva no lugar de gestão individual;

4. O apoio ou assistência (ajuda) a um membro do grupo;

5. O momento de compartilhar pontos de vista e divergências;

6. O equilíbrio dos esforços individuais;

7. O desenvolvimento das capacidades de cada um do grupo;

8. O conhecimento dos membros do grupo sobre o funcionamento da instituição;

9. O compartilhamento de ações significativas sobre conflitos e habilidades de reorganização do trabalho;

10. A confiança mútua no que o outro faz;

11. A construção de um gênero profissional autorizando os estilos individuais;

12. O bom acolhimento e recepção do novato;

13. A transmissão dos conhecimentos relativos ao métier;

14. Entre outras possibilidades ${ }^{8}$.

Com as características de vitalidade, podemos também discutir em que medida o coletivo está ou não sendo vital na realização cotidiana das atividades de trabalho, bem como apontar aspectos que estejam desvitalizando-o (DIOLINA, 2016), isto é, gerando dificuldades para a ação conjunta, para a troca de conhecimentos, para a inteligência mútua, para o desenvolvimento da atividade de trabalho, como a dos professores que analisamos a seguir.

\section{Os procedimentos metodológicos}

Nesta seção, objetivamos descriminar os procedimentos metodológicos, esclarecendo o contexto de pesquisa e os procedimentos de coleta, de seleção e de análise dos dados, conforme detalhado nas subseções abaixo.

\section{Contextualizando}

A pesquisa de doutorado ${ }^{9}$ deu-se em uma instituição escolar da rede pública estadual da grande São Paulo, em Guarulhos $/ \mathrm{SP}^{10}$. A instituição investigada oferecia cursos regulares do $2^{\circ}$ Ciclo do Ensino Fundamental Básico $-5^{\mathrm{a}}$ a ${ }^{6 \mathrm{a}}$ série $\left(6^{\circ}\right.$ ao $9^{\circ}$ ano), do período das $13 \mathrm{~h}$ às $18 \mathrm{~h} 20$, com 638 alunos matriculados; e do Ensino Médio, das 7h às 12h20, com 521 alunos matriculados, em 2013, ocasião da coleta de dados. Fundada em 1979, situa-se próxima ao centro, tendo fácil acesso para quem vem de outros bairros do município e, segundo os gestores e os professores, é bem avaliada pela comunidade da cidade, o que intensifica a procura por vagas na escola, contribuindo para uma comunidade escolar bem heterogênea com alunos oriundos de diferentes regiões da cidade.

Os professores-participantes somaram oito, formando dois grupos. Grupo I formado por três professoras (História, Português e Ciências) e Grupo II formado por cinco professores (três de Matemática, um de Artes e um de Sociologia). Os grupos foram formados em razão do horário das Atividades de Trabalho Pedagógico Coletivo (ATPC) $)^{11}$. Os professores do Grupo I participavam das ATPC's pela manhã e os do Grupo II, pela tarde. Daí a necessidade de dividi-los em grupo e de desenvolver a pesquisa em períodos distintos.

Os dados que integram este artigo foram coproduzidos pelas professoras-participantes do Grupo I e pela pesquisadora. A pesquisadora, na ocasião da pesquisa, era professora efetiva do ensino técnico SENAI e bolsista CNPq em doutorado. Quanto às professoras, as três lecionavam disciplinas distintas (História, Português e Ciências), sendo que a de História e a de Português eram professoras efetivas na instituição e a de Ciências, contratada.

As diferenças de disciplinas, de categorias e de tempo de trabalho são aspectos importantes do contexto por representar a realidade vivida pelos professores em ATPC (Atividade de Trabalho Pedagógico Coletivo). Em outros termos, buscamos respeitar e nos aproximar das condições concretas de trabalho dos professores da instituição, criando grupos heterogêneos, pois consideramos a escola 
um espaço heterogêneo (de classes, gêneros, credos, culturas, histórias etc.) e no coletivo dos professores não é diferente. O que nos alerta quanto a uma visão antecipada e apressada de como representar o coletivo de professores, isto é, de conceber como ele se constitui, de como ele funciona e atua, de como ele se sustenta etc.

Atentos, detalhamos nossos procedimentos metodológicos, conforme segue.

Os procedimentos de coleta, de seleção e de análise dos dados

As atividades desenvolvidas com os professores-participantes, durante a pesquisa de doutorado, deram-se em etapas distintas, mas complementares, a saber: (i) a realização da instrução ao sósia com cada participante dos Grupos; (ii) discussão em grupo com base nas instruções dadas; (iii) e retorno ao coletivo de trabalho, finalizando as atividades propostas.
A instrução ao sósia ${ }^{12}$ foi fundamental para que pudéssemos discutir a atividade de trabalho do professor de forma objetiva e clara, pois, após sua realização, a leitura das intruções dadas pelos professores serviram de instrumento para selecionar situações, desafios, estratégias, mal entendidos, revisões das instruções etc., construindo coletivamente uma pauta para os encontros de discussão em grupo. Após a seleção dos tópicos a serem discutidos, a pesquisadora organizanisou-os numa pauta, tomando por referência o triângulo da atividade de trabalho docente (MACHADO, 2007), em especial: os tópicos relativos ao objeto (à organização do meio); e a outrem (alunos, pais, gestores, funcionários). A forma de organização possibilitou encontros de discussão mais bem direcionados, conforme exempleficado no quadro abaixo.

Figura 2: Quadro explicativo da pauta de discussões em grupo

\begin{tabular}{|l|l|l|}
\hline $\begin{array}{l}\text { Triângulo da } \\
\text { atividade }\end{array}$ & $\begin{array}{l}\text { Tópicos } \\
\text { temáticos }\end{array}$ & Intrução ao sósia \\
\hline $\begin{array}{l}\text { Organização } \\
\text { do ambiente } \\
\text { da sala de aula } \\
\text { aos demais } \\
\text { ambientes da } \\
\text { escola) }\end{array}$ & $\begin{array}{l}\text { Sala difícil; } \\
\text { Indisciplina; } \\
\text { Lugar dos alunos } \\
\text { na aula. }\end{array}$ & $\begin{array}{l}\text { H...] Você vai chegar e essa sala está um pouquinho pavorosa. Então, você vai } \\
\text { entrar e vai esperar um tempo até eles perceberem a sua presença. }\end{array}$ \\
$\begin{array}{l}\text { PESQ - E aí? Eu fico em silêncio? } \\
\text { H - Muito silêncio. Uma cara bastante séria. Isso, porque mesmo se você tentar } \\
\text { alterar a voz, o barulho é muito grande, então você vai precisar alterar muito a voz. } \\
\text { Se caso continuar e você perceber que precisa, aí sim, você levanta a voz], fala } \\
\text { mais alto, fala que a aula já começou. Aí, eles vão começando a se organizarem. }\end{array}$ \\
$\begin{array}{l}\text { É:.::: esta sala, esta semana, eu comecei a colocar uma... Uma organização melhor. } \\
\text { Não é exatamente um mapeamento, mas eles ficavam muito no fundo. Então, } \\
\text { agora eles estão mais.... Puxei eles um pouco pra frente. Então, quando você } \\
\text { chegar faça isso, veja se eles estão muito no fundo e traga-os pra frente. }\end{array}$ \\
\hline
\end{tabular}

Fonte: DIOLINA (2016).

Com as pautas em mãos, os encontros de discussão com o Grupo I ocorreram no dia $30 / 10 / 2013$ e no dia 07/11/2013. Os dados aqui analisados foram produzidos no dia 30/10/2013, com discussões entre as professoras e a pesquisadora sobre a atividade docente, o que fez emergir muitos temas relativos a desafios e estratégias em diversas situações. Devido ao grande volume de dados transcritos, optamos por selecionar excertos denominados de situações desafiantes que tratam de um tema, de uma situação, de uma condição embaraçosa, de algo que instigue, que provoque $\mathrm{o}$ professor a agir conforme as possibilidades e os objetivos que se tem. Em outros termos, excertos sobre situações que exijam do professor estratégias (positivas ou negativas) para sanar os impedimentos, ou ainda, que apontem para aqueles intransponíveis na atividade de trabalho.

Essencialmente, consideramos os encontros de discussão em grupo como um espaço privilegiado de trocas de experiências, de representações, de embates, de interação, de coprodução textual, fornecendo elementos fundamentais para a compreensão entre estilos individuais e coletivos. Segundo Clot (2010) "é somente na interação dos homens que se desvela 'o homem no homem' tanto para os outros como ele mesmo" (CLOT, 2010, p. 131). As discussões em grupo, então, possibilitaram a reinterpretação, a ressignificação da atividade de trabalho, tanto a dos estilos individuais como a dos coletivos.

Para análise dos dados, advertimos que compreendemos o agir humano como uma "obra aberta, um fenômeno cuja significação continua 
suspensa e que se torna, portanto, necessariamente, objeto de interpretações" (BRONCKART, 2006, p.70, grifo do autor). Interpretações que dependem de parâmetros ou de representações que são "sistemas de coordenadas formais" a partir das quais o agir pode ser situado e avaliado (BRONCKART, 2006, p. 70).

Esses sistemas consistem num quadro social gerador de convenções e de comportamentos em que as modalidades do agir se inscrevem e se validam, em que o indivíduo busca "'ornar' sua ação de características singulares" aos traços do coletivo (BRONCKART, 2006, p. 70, grifo do autor), numa tensão em que pode promover a transformação e o desenvolvimento humano. Daí a importância de analisar textos (orais ou escritos), que são os correspondentes empíricos da atividade de linguagem (BRONCKART, 2006), sobre o agir do professor, uma vez que podemos identificar os parâmetros consolidados, refutados, almejados, idealizados, bem como as representações das condutas singulares e coletivas, conforme expressas pelos professores participantes desta pesquisa.

Para tanto, recorremos ao quadro teóricometodológico do ISD, conforme Machado e Bronckart (2009), particularmente, centramo-nos nos aspectos contextuais, organizacionais, enunciativos e semânticos dos textos. Os aspectos contextuais são importantes já que compreendemos os contextos (sócio-histórico, físico e sociossubjetivo) como elementos que influenciam diretamente na produção textual (MACHADO; BRONCKART, 2009). Os aspectos organizacionais revelam o plano, o encadeamento dos temas, o tipo de discurso e as sequências textuais que estruturam, organizam o texto, e que podem nos oferecer informações sobre como a figura do protagonista e aspectos de seu agir estão sendo construídos nos textos. Os aspectos enunciativos oferecem recursos para investigarmos "os mecanismos de responsabilização enunciativa em geral" (MACHADO; BRONCKART, 2009, p. 58) e de posicionamentos do enunciador, por meio da gestão de vozes introduzidas no texto e pelas modalizações. Por fim, o nível semântico fornece condições de se produzir uma análise mais micro sobre as representações configuradas nos textos (MACHADO; BRONCKART, 2009). Trata-se da análise de verbos e de nominalizações que se referem ao agir, em prol das representações acerca da atividade do professor, conforme configuradas no texto.

Embora o quadro teórico-metodológico do ISD sustente nossas análises, buscamos também os aportes da Clínica da Atividade, os do Grupo ERGAPE e as características de vitalidade do coletivo para melhor apreensão da atividade de trabalho do professor e do papel do coletivo, conforme apresentamos a seguir. Nesta apresentação, não traremos em detalhes toda a análise, mas apenas os aspectos que contribuirão para a nossa discussão.

\section{Os resultados e discussões de análises}

O objetivo desta seção é apresentar os resultados e discussões das análises dos dados, particularmente, o segmento que tematiza uma situação desafiante em que os professores se referem à estratégia coletiva denominada por eles de "o combinado".

Os dados foram produzidos em 2013. Nesse ano, o Brasil marcou sua história políticosocial com as manifestações de junho, com a mobilização da população em protestos no país e no exterior contra a baixa qualidade dos serviços públicos na saúde, no transporte, na segurança pública e, em especial, na educação.

Em relação à educação, antes mesmo das manifestações, os professores do estado de São Paulo junto à APEOESP (Sindicato dos Professores do Ensino Oficial do Estado de São Paulo) organizaram uma greve em abril/2013. Na escola onde se deu a pesquisa, os professores haviam participado da greve e demonstravam relação estreita com o sindicato, destacando em suas conversas seus direitos e deveres, inclusive citando leis e artigos (o que foi possível constatar durante as visitas e observações na escola).

O Grupo I foi constituído por duas professoras efetivas (sendo uma de História e outra de Português) e uma professora contratada (de Ciências). As professoras efetivas trabalhavam na escola em torno de 4 e 5 anos, respectivamente. E a contratada, há apenas 2 anos. Embora sejam apenas dois anos como contratada, a professora vivia uma situação diferenciada e privilegiada, já que é difícil para o docente nesta situação retornar para a mesma instituição, devido à classificação dos professores no processo seletivo e à disponibilidade de turmas nas escolas que oscilam ano a ano (DIOLINA, 2017). 
O lugar disponível para os encontros em grupo deu-se na própria instituição, em horário de ATPC (Atividades de Trabalho Pedagógico Coletivo), quinzenalmente. Com o Grupo I, foram dois ATPC's, conforme estabelecido pelos professores e pela gestão escolar, o que marca um tom formal, institucionalizado aos encontros. As ATPC's ocorriam com professores de diferentes turmas, disciplinas, categorias etc., o que procuramos manter, respeitando e nos aproximando das condições concretas de trabalho dos professores.

As professoras introduziram temas que, de maneira geral, centravam-se ou nas estratégias ou nos desafios vividos diariamente. Ainda que os termos, "desafio" ou "estratégia", não fossem mencionados, os temas introduzidos pelas professoras indiretamente referiam-se a eles. As estratégias e os desafios versam tanto sobre as diferentes formas de atuar na organização da turma, quanto sobre as diversas relações humanas e suas consequências, mas também sobre outros aspectos, como a divisão da profissão em categorias (efetivos, contratados, eventuais) e as consequências dessa divisão para a profissão (DIOLINA, 2017).

A estratégia do "combinado" foi uma das mais discutida e apontadas como recurso na organização do meio, na coordenação da turma, conforme o trecho a seguir.

\section{Grupo I}

$208^{\circ}$ P: Isso, en estou te falando daquela questão de que podia contar com alguns colegas. Nós combinamos isso. É... os professores não faltam. Né? A maioria. Um, outro combinado que nós tivemos, foi com outra sala... Foi matemática? Mas a professora sumiu. E ela (a nova professora) está se adequando. Né? Está ainda conhecendo a escola. Mas em relação à organização... Até a Nivalda que é eventual, entrava comigo, falava a mesma coisa: fulano sentado, beltrano aqui é assim. (...) eu já havia combinado com as outras professoras: "vou fazer dessa maneira".

$210^{\circ}$ P: Sempre, eu comentava com o grupo, com o colega: "olha, vou fazer assim". E eles (professores) comentavam: "Olha Paula, vou fazer de tal forma". E quando eles (alunos) falavam alguma, usavam o nome do professor, eu dizia: "Por favor, chama o professor para vir aqui e a gente vai tirar essa dúvida". Eu sabia que ela (outra professora) não havia agido daquela maneira. É porque tem uma confiança uma com a outra.

No excerto acima, a situação refere-se à estratégia do "combinado", do acordo entre professores e a professora de Português (Paula), devido a uma turma indisciplinada da escola. $\mathrm{O}$ turno $208^{\circ}$ detalha que o combinado é um acordo feito entre um grupo de professores que dá aula para uma mesma turma, conforme o trecho "um, outro combinado que nós tivemos, foi com outra sala... Mas a professora sumiu. E ela (a nova professora) está se adequando...". Nesse trecho, a professora retoma um combinado que sofreu com a mudança de professores, logo a falta de assiduidade, a rotatividade de professores pode desvitalizar o coletivo, conforme o excerto a seguir: "nós combinamos isso. É... os professores não faltam. Né?". Nesse exemplo, podemos dizer que a assiduidade dos professores é uma característica de vitalidade do coletivo, pois alimenta as características relativas ao equilíbrio dos esforços individuais, ao desenvolvimento das capacidades de cada um, bem como favorece a troca de práticas significativas.

A estratégia "o combinado" implica em um comportamento, em uma maneira de agir (de trabalhar) com a turma, "eu já havia combinado com as outras professoras: 'vou fazer dessa maneira". Também existe uma linguagem comum: "Até a Nivalda que é eventual, entrava comigo, falava a mesma coisa: 'fulano sentado, beltrano aqui é assim"'. Logo, existe um agir linguageiro de "combinar", que pode ser interpretado, segundo a professora, como, "[poder] contar com alguns colegas". Nesse exemplo, evidencia-se o agir experiente, por meio da modalização pragmática em que a professora "...podia contar". Evidencia-se também as características de confiança mútua e de apoio, assistência a um membro. A professora Paula traz a sua voz e a dos demais professores para marcar como o agir linguageiro tornou-se um recurso em prol da atividade de cada professor do grupo, numa construção de regras comuns e de legitimação de estilos individuais e coletivos, desenvolvendo o gênero profissional.

O protagonismo do "combinado" dá-se pela expressiva marca à coletividade, por meio dos pronomes "nós" / "eles" e dos nomes "professores" / "professoras". A professora enunciadora também está implicada na situação com o uso do pronome "eu" e com verbos que retomam o passado, evidenciando o discurso relato interativo. A sequência é narrativa, existe uma história, isto é, a professora narra a sua experiência na elaboração conjunta da estratégia "combinado", em que há fatores complicadores (falta de assiduidade dos professores, comportamento dos alunos) e tomadas de decisão em virtude desses complicadores. O caráter moral da história pode ser inferido pela questão relativa à confiança entre os professores

Horizontes, v. 35, n. 3, p.71-82, set./dez. 2017 
“O combinado” entre professores: marcas da (des)vitalidade do coletivo

sobre o modo de agir do colega.

No "combinado", reafirmamos que, além do uso da mesma linguagem com os alunos, há um modo de fazer (um agir experiente) já previsto entre os professores (instância inter e transpessoal). O combinado em particular refere-se a um acordo sobre o que falar e como agir com os alunos, existe um agir comunicacional que gera o agir praxiológico: "Sempre, eu comentava com o grupo, com o colega: 'olha, vou fazer assim'. E eles (professores) comentavam: 'Olha Paula, vou fazer de tal forma". O advérbio "sempre" marca uma circunstância que se repete, contínua, em que os professores estão em interação continuamente. As vozes dos professores são retomadas para sublinhar um agir legitimado pelo grupo: uma autoprescrição na construção de regras comuns e na troca de ações significativas para a solução dos desafios diários da profissão. Nas palavras de Caroly e Barcellini (2013), existe, então, a articulação do trabalho coletivo em que os professores se engajam e do coletivo de trabalho do qual eles compartilham modos de agir.

A professora Paula também adverte sobre uma situação embaraçosa que poderia quebrar a estratégia, mas que na verdade ajuda a reforçar como "o combinado" é levado a sério por ela e pelos colegas. Paula refere-se a um agir experiente (eu sabia) para apontar o nível de confiança mútua entre os professores: "Eu sabia que ela (outra professora) não havia agido daquela maneira. É porque tem uma confiança uma com a outra". Para que a estratégia funcione, é imprescindível a relação de confiança mútua entre os colegas, $\operatorname{logo}$ a transgressão dos modos de agir elaborados e legitimados pelo grupo pode prejudicar a estratégia.

Em suma, os resultados apontam e alertam para a importância de determinadas características relativas à estratégia do "combinado", como, a força do grupo de professores que ministram aula para a mesma turma, já que são professores que vivenciam um contexto em particular, uns com mais, outros com menos dificuldades, porém todos com certa expertise e perspectiva sobre esse mesmo contexto, turma, sala. Como a situação em que estão inseridos é a mesma, logo a construção de objetivos comuns é favorecida, o que é vital para a constituição e o fortalecimento do coletivo seja nas instâncias inter ou transpessoal. Embora a estratégia do "combinado" nos pareça simples, nem sempre os professores têm em seu convívio a oportunidade e a confiança mútua necessária para dividir seus desafios e construir, com o outro, estratégias em prol de seu poder de agir. Identificar essas situações, ou mesmo, promovê-las pode trazer benefícios para a atividade de trabalho do professor e, consequentemente, para todos envolvidos, já que a educação é fenômeno social.

\section{Considerações finais}

Dado o nosso objetivo de problematizar o papel do coletivo na produção de soluções em razão dos desafios diários vividos pelos professores, consideramos que o papel do coletivo se mostrou efetivo, vital, ainda que alguns aspectos das condições de trabalho visem a desvitalizá-lo, como: a falta de assiduidade, a rotatividade de professores e a possível transgressão dos modos de agir elaborados e legitimados pelo grupo (DIOLINA, 2016). Entretanto, por meio da estratégia do combinado, o grupo de professores criou um espaço para a troca de experiências, para o apoio ou a assistência aos membros do grupo, para a manutenção da harmonia do trabalho, para a construção de regras em comum, para a legitimação de modos de agir, para o fortalecimento da confiança mútua, promovendo um processo de desenvolvimento e de transformação do gênero profissional. Essas características são fundamentais para a vitalidade do coletivo, apontam para a capacidade do grupo em se ajustar e, em superar os impedimentos da atividade de trabalho. Existe um objetivo em comum, mas, sobretudo, modos de fazer significativos compartilhados e transformados por meio das trocas na interação com o outro. $\mathrm{O}$ papel do coletivo é, portanto, o oxigênio dialógico (CLOT, 2015) na mediação das tensões sentidas na realização da atividade de trabalho.

\section{Notas}

1 O III Colóquio Internacional de Clínica da Atividade (CICA) foi realizado na Universidade de São Paulo - USP pela Faculdade de Filosofia, Letras e Ciências Humanas (FFLCH), de 19 a 21 de outubro. Reuniu uma comissão organizadora composta por membros de três universidades do Estado de São Paulo (USP, UNICAMP e Universidade São Francisco) e teve como objetivo retomar os principais aportes teóricosmetodológicos da Clínica da Atividade, 
colocando-os em discussão no âmbito das pesquisas desenvolvidas atualmente no Brasil e na França. Ver: http://cica2016.fflch.usp.br/

2 Grupo, idealizado e criado pela Professora Doutora Anna Rachel Machado (in memoriam) nos anos 90, atualmente, com sede na USP, desenvolve/desenvolveu inúmeras pesquisas relativas à Análise da Linguagem, o Trabalho Educacional e suas Relações.

3 Ressaltamos que os professores participaram de encontros de discussão em grupo (textos orais, posteriormente transcritos) que tematizavam tanto sobre os desafios diários da profissão, como sobre as estratégias utilizadas por eles. Somaram-se oito encontros de discussão e devido ao grande volume de dados, durante a seleção e o tratamento de dados, o corpus foi organizado em diferentes trechos temáticos que denominamos de "situações desafiantes".

4 Clot e Faïta (2000) propõem os gêneros técnicos que formam o regime de utilização das técnicas e gestos dentro de um meio. Eles fazem "a ponte entre a operacionalidade formal e prescrita (regras) dos recursos materiais e dos modos de agir e de pensar um meio" (CLOT; FAÏTA, 2000, p. 12, tradução nossa)

5 Ils sont les présupposés sociaux de l'activité en cours, qui donne sa contenance à l'activité personnelle: s'adresser, manières de commencer une activité et de la finir, manières de la conduire efficacement (CLOT; FAÏTA, 2000, p. 12, tradução e adaptação nossa).

6 «Une articulation du travail collectif dans lequel les opérateurs/trices sont engagé/s e du collectif de travail auquel ils/elles appatiennent» In: CAROLY; BARCELLINI $\left(201^{3}\right.$, p. 01).

$7 \ll$ Ces quatre instances sont structurellement liées, en tension, en conflit, et de la fluidité de leurs rapports dépendent les questions de santé et d'efficacité au travail: tout est lié; ou du moins devrait l'être pour que la vitalité professionnelle ne se dissipe pas » (KOSTULSKI, et al., 2011, p.134, tradução e adaptação nossa).

8 A décima quarta característica é aquela que está para ser desvendada em um determinado momento e meio profissional. A autora faz questão de mantê-la em aberto, reforçando a ideia do quanto é importante estarmos atentos às novas características de vitalidade do coletivo estudado.

9 Aprovada no Comitê de Ética da PUC/SP., conforme Resolução CNS 196/96. Disponível em: http://aplicacao.saude.gov.br/plataformabrasil/vis ao/publico/indexPublico.jsf
10 Atualmente, é o segundo maior município paulista em população, com mais de 1.221.979 habitantes segundo dados do Censo do IBGE (2010). Localizada na Região Metropolitana de São Paulo, com apenas $17 \mathrm{~km}$ de distância de São Paulo (a maior metrópole do Brasil). Em 1985, a inauguração do aeroporto internacional de Guarulhos trouxe grande desenvolvimento para a cidade. Disponível em: http://www.guarulhos.sp.gov.br

11 As Atividades de Trabalho Pedagógico Coletivo (ATPC) referem-se a um momento de trabalho coletivo (com os demais professores de seu período) obrigatório a todos os professores com supervisão da gestão. É um encontro entre professores e coordenação (gestão), sendo que a coordenação orienta as atividades para a formação do professor (p. ex. metodologias, relação aluno-professor, elaboração de planejamento etc.), esclarece dúvidas, discute problemas e propostas.

$12 \mathrm{O}$ procedimento de Instrução ao Sósia assemelha-se a uma entrevista do sósia (pesquisador) com $\quad \mathrm{o}$ instrutor (profissional/professor), em que as questões são relativas ao modo de fazer determinada atividade de trabalho. As perguntas (questões do sósia/pesquisador) e as respostas (ou orientações do profissional/instrutor) visam aos detalhes de como realizar a atividade de maneira que ninguém do contexto de trabalho perceba uma suposta e fictícia substituição do profissionalprofessor pelo sósia-pesquisador. Essa interação entre eles é gravada em áudio e, posteriormente, transcrita para leitura, análise e discussões posteriores. Para maiores detalhes, ver Clot (2006, 2010), DIOLINA (2016, p. 92) - Parte II, Cap. IV, Procedimentos de coleta, de confiabilidade e de seleção dos dados.

\section{Referências}

AMIGUES, R. Trabalho do professor e trabalho de ensino. In: MACHADO, A. R. (Org.) $O$ ensino como trabalho: uma abordagem discursiva. Tradução Anna Rachel Machado. Londrina. Eduel: 2004, p. 35-53.

BRONCKART, J-P. Atividades de linguagem, textos e discursos: por um interacionismo sociodiscursivo. Tradução de Anna Raquel Machado e Péricles Cunha. São Paulo: Educ. 2a . ed., 
1999, 353p.

Atividade de

linguagem, discurso e desenvolvimento humano. Organização Anna Rachel Machado e Maria de Lourdes Meirelles Matencio. Tradução Anna Rachel Machado e Maria de Lourdes Meirelles Matencio [et al]. Campinas, SP.: Mercado de Letras - (coleção ideias sobre linguagem), 2006, 258p.

CAROLY, S. Activité collective et réélaboration des règles: des enjeux pour la santé au travail. Document d'habillitation à diriger des recherches en ergonomie. Université de Bordeaux, 2010. Disponível em: http://tel.archives-ouvertes.fr/tel00464801/fr/ . Acesso em 15 de agosto de 2017.

CAROLY, S.; BARCELLINI, F. Le développement de l'activité collective. In: FALZON, P. (Coord.) Ergonomie Constructive. Paris, France: PUF., 2013, p. 33-46.

CLOT, Y.; FAITTA, D. Genres et styles em anlyse $d u$ travail. Concepts et méthodes. Travailler, n.4, 2000, p. 7-42.

CLOT, Y. A Função Psicológica do Trabalho. Trad. Adail Sobral - Petrópolis, RJ: Vozes, $2^{\mathrm{a}}$ ed., 2006, 222p.

Trabalho e poder de agir. Tradução de Guilherme João de Freitas Teixeira e Marlene Machado Zica Vianna. Belo Horizonte: Fabrefactum: 2010, 358p. (Série Trabalho e Sociedade).

Notas de aula durante curso PST 106 - Psychologie du travail et clinique de l'activité, ministrado por Yves Clot, em 17 de Abril de 2015 (das 18h às 21h) no Conservatoire des Arts et Métier, Paris/França.

DIOLINA, Kátia. Quem ensina, aprende a vencer os desafios da profissão: o papel do coletivo. 2016. 238p. Tese (Doutorado em Linguística Aplicada e Estudos da Linguagem), Pontifícia Universidade Católica de São Paulo: São Paulo, 2016.

O professor temporário e o papel do coletivo: marcas da (des)vitalidade do métier.
Revista de Estudos Linguísticos Veredas. Volume especial: $\mathrm{O}$ Interacionismo Sociodiscursivo. Volume 21, Número 3, p. 424 - 443 - PPG Linguística/UFJF - Juiz de Fora (MG), 2017.

ESTEVE, J. M. O mal-estar docente - A sala de aula e a saúde dos Professores. Trad. Durley de Carvalho Cavicchia. Bauru: EDUSC, 1999.

JEDLICKI, L.R.; YANCOVIC, M.P. Desprofissionalização docente. In: OLIVEIRA, D.A.; DUARTE, A.M.C.; VIEIRA, L.M.F. DICIONÁRIO: trabalho, profissão e condição docente. Belo Horizonte: UFMG/Faculdade de Educação, 2010, Disponível em: http://www.gestrado.net.br/?pg=dicionarioverbetes\&id=400 . Acesso em 20 de junho de 2017.

KOSTULSKI, K., CLOT, Y., LITIM, M., PLATEAU, S. L'horizon incertain de la transformation en clinique de l'activité: une intervention dans le champ de l'éducation surveillée. Activités: 2011 p. 129-145, http://www.activites.org/v8n1/v8n1.pdf. Acesso em 16 de agosto de 2017.

MACHADO, A.R. Por uma concepção ampliada do trabalho do professor. In: GUIMARÃES, A.M.M; MACHADO, A.R.; COUTINHO, A. (Orgs.) $O$ Interacionismo Sociodiscursivo: questões epistemológicas e metodológicas. Campinas/SP: Mercado de Letras, 2007, p. 77-97. (Série Ideias sobre Linguagem)

MACHADO, A.R.; BRONCKART, J-P. (Re)configurações do trabalho do professor construídas nos e pelos textos. In: $O$ trabalho do professor em uma nova perspectiva. Anna Rachel Machado; Vera Lúcia Lopes Cristóvão, Lilia Santos Abreu-Tardelli (orgs): posfácio Jean-Paul Bronckart - Campinas, SP.: Mercado de Letras, 2009, p.31-78. (Série ideias sobre Linguagem)

MACHADO, A. R.; MAGALHÃES, M. C. A assessoria a professores na universidade brasileira: a emergência de uma situação de trabalho a ser desvelada. In: SOUZA-E-SILVA; M. C. P.; FAÏTA, D. (Org.). Linguagem e trabalho: construção de objetos de análise no Brasil e na França. São Paulo: Cortez, 2002, p. 139-156. 


\section{Sobre as autoras}

Kátia Diolina é pós-doutoranda (CAPES-PNPD) no Programa Stricto Sensu em Educação, da linha de pesquisa em Educação, Linguagens e Processos Interativos, da Universidade São Francisco, Campus Itatiba/SP. Doutora e mestre (bolsista CNPq) pelo Programa de pós-graduação em Linguística Aplicada e Estudos da Linguagem (LAEL) na Pontifícia Universidade Católica de São Paulo. Desenvolve pesquisas quanto às relações de linguagem e trabalho educacional, bem como sobre os estudos dos gêneros textuais e do letramento no processo de ensino.

Luzia Bueno é Professora doutora do Programa Pós-Graduação Stricto Sensu em Educação, da linha de pesquisa Educação, Linguagens e Processos Interativos, da Universidade São Francisco. Mestre em Linguística Aplicada pela Unicamp, doutora em Linguística Aplica pela PUC-SP, com estudos pós-doutorais em Letramento pela Unicamp. Desenvolve e orienta pesquisas sobre trabalho docente, letramento e gêneros textuais.

Recebido em julho de 2017.

Aprovado em setembro de 2017. 